\title{
Intersectin Is a Negative Regulator of Dynamin Recruitment to the Synaptic Endocytic Zone in the Central Synapse
}

\author{
Emma Evergren, ${ }^{\star}$ Helge Gad, ${ }^{\star}$ Kristin Walther, ${ }^{\star}$ Anna Sundborger, Nikolay Tomilin, and Oleg Shupliakov \\ Department of Neuroscience, Karolinska Institutet, 17177 Stockholm, Sweden
}

\begin{abstract}
Intersectin is a multidomain dynamin-binding protein implicated in numerous functions in the nervous system, including synapse formation and endocytosis. Here, we demonstrate that during neurotransmitter release in the central synapse, intersectin, like its binding partner dynamin, is redistributed from the synaptic vesicle pool to the periactive zone. Acute perturbation of the intersectin-dynamin interaction by microinjection of either intersectin antibodies or Src homology 3 (SH3) domains inhibited endocytosis at the fission step. Although the morphological effects induced by the different reagents were similar, antibody injections resulted in a dramatic increase in dynamin immunoreactivity around coated pits and at constricted necks, whereas synapses microinjected with the GST (glutathione $S$-transferase)-SH3C domain displayed reduced amounts of dynamin in the neck region. Our data suggest that intersectin controls the amount of dynamin released from the synaptic vesicle cluster to the periactive zone and that it may regulate fission of clathrin-coated intermediates.
\end{abstract}

Key words: presynaptic mechanisms; synaptic vesicle recycling; ultrastructure; periactive zone; glutamatergic neurons; spinal cord

\section{Introduction}

Clathrin-mediated endocytosis is one of the major pathways for synaptic vesicle recycling (Murthy and De Camilli, 2003; Granseth et al., 2006). Along with numerous other proteins implicated in this process, the GTPase dynamin is a key element that is required for the fission of newly formed vesicles from the plasma membrane. Recent in vitro studies have provided clues about how dynamin functions in fission (Chen et al., 2004; Roux et al., 2006). However, it is still unclear how the protein is delivered to coated intermediates to perform its function. It is believed that the C-terminal PRD (proline-rich domain) plays an important role. This domain interacts with Src homology 3 (SH3) domains of several endocytic proteins enriched in synapses such as amphiphysin, endophilin, syndapin, and intersectin (Praefcke and McMahon, 2004; Anggono et al., 2006). All of these proteins have been implicated in specific protein-protein and protein-lipid interactions in the synapse, suggesting that they are interacting with dynamin at particular steps of the vesicle cycle. In addition, some of these interactions are modulated by phosphorylation, which involves proteins such as calcineurin and Cdk5 (cyclin-

\footnotetext{
Received July 13, 2006; revised Nov. 27, 2006; accepted Nov. 27, 2006.

This work was supported by grants from the Swedish Research Council (13473), Svenska Läkaresällskapet, the Swedish Royal Academy, the Wallenberg Foundation, and Erik Fernström's Foundation (0.S.). H.G. was supported by the Swedish Brain Foundation, N.T. received support from the Russian Foundation for Basic Research (05-04-08973), and K.W. received stipends from the Wenner-Gren Foundation and the Deutsche Forschungsgemeinschaft. We thank Drs. H. T.McMahon, P. McPherson, and T. Südhoffor the generous gift of intersectin and Eps 15 antibodies, Drs. L. Brodin and P. DeCamilli for the generous gift of dynamin and amphiphysin antibodies, and Dr. P. Greengard for the random-primed cDNA library and synapsin antibodies. We thank Dr. P. Löw for expert advice and Drs. H. Bellen, H. T. McMahon, P. DeCamilli, S. Schmid, and D. Parker for discussions and critical comments.

*E.E., H.G., and K.W. contributed equally to this work.

Correspondence should be addressed to Dr. Oleg Shupliakov, Department of Neuroscience, Karolinska Institutet, 17177 Stockholm, Sweden. E-mail: Oleg.Shupliakov@ki.se.

DOI:10.1523/JNEUROSCI.4683-06.2007

Copyright $\odot 2007$ Society for Neuroscience $\quad$ 0270-6474/07/270379-12\$15.00/0
}

dependent kinase 5), further indicating that specific interactions dominate in resting synapses, whereas others occur during activity (Cousin et al., 2001; Anggono et al., 2006).

The role of the scaffolding protein intersectin in vertebrate synapses remains obscure. Two intersectin genes (1 and 2) have been identified, each producing long $(\mathrm{L})$ and short isoforms with many splice variants (Guipponi et al., 1998; Pucharcos et al., 2000). Only the long isoform of intersectin 1 is selectively expressed in neurons. Intersectin $1 \mathrm{~L}$ consists of two epidermal growth factor receptor pathway substrate clone 15 (Eps15) homology (EH) domains along with a coiled-coil domain, which bind epsin 1/2, Eps15, stoned B/stonin 2, SNAP-25 (synaptosome-associated protein of $25 \mathrm{kDa}$ ) (Okamoto et al., 1999; Sengar et al., 1999; Martina et al., 2001), and five SH3 domains located in the middle part; three of these interact with dynamin. In addition, synapsin, synaptojanin, and stoned B/stonin 2, the Arp2/3 (actin-related protein 2/3)-interacting protein, neuronal Wiskott-Aldrich syndrome protein (NWASP), and a signaling protein, Sos (son of sevenless), have also been identified as binding partners for this region (Tong et al., 2000; Hussain et al., 2001; Zamanian et al., 2003). Intersectin 1L also possesses a $\mathrm{PH}$ (pleckstrin homology) domain, which interacts with phospholipids, and a DH (Dbl homology) domain, which functions as a GEF (guanine nucleotide exchange factor) for Cdc42 (Zamanian et al., 2003), indicating a potential role for intersectin in the organization of the actin cytoskeleton (Hussain et al., 2001; McPherson, 2002). Loss-of-function mutations of the Drosophila ortholog of intersectin, dynamin-associated protein of $160 \mathrm{kDa}$ (Dap160), are lethal, demonstrating that the gene is essential (Koh et al., 2004; Marie et al., 2004). Null mutant flies show severe defects in the formation of neuromuscular junctions (NMJs) and in synaptic vesicle recycling (Koh et al., 2004; Marie et al., 2004). These data suggest that intersectin may play an im- 
portant role in sustaining neurotransmitter release in vertebrate synapses.

In this study, we investigated the role of intersectin-dynamin interactions in synaptic vesicle recycling by using the lamprey giant reticulospinal synapse as a model system. We show that intersectin redistributes to sites of clathrin-mediated endocytosis from the synaptic vesicle cluster during activity and controls the amount of dynamin destined for migration to the periactive zone. In addition, our data suggest that intersectin is involved in the regulation of fission.

\section{Materials and Methods}

Cloning of lamprey intersectin. Using the QuickPrep mRNA Extraction kit (GE Healthcare, Little Chalfont, UK), mRNA was isolated from lamprey (Lampetra fluviatilis) brain. cDNA was synthesized with the ThermoScript reverse transcriptase (Invitrogen, Carlsbad, CA) and random or oligo-dT primers. An intersectin ortholog was partially cloned using degenerate primers against the conserved $\mathrm{SH} 3$ domain region and a random-primed lamprey brain cDNA. The resulting bands were subcloned into the pCR2.1-TOPO vector (Invitrogen) and sequenced. Sequencing was performed at KISeq, Karolinska Institutet (Stockholm, Sweden). Using oligo-dT- and random-primed cDNA, additional independent clones were generated confirming the found sequence. $3^{\prime}$ RACE (rapid amplification of cDNA ends) was performed using an oligo-dTprimed lamprey brain cDNA, a specific primer from the $3^{\prime}$ end of the obtained sequence, and an oligo-dT primer. This clone contained an in-frame stop codon followed by an $\sim 1300 \mathrm{bp}$ untranslated region and ended with a poly-A tail. The $5^{\prime}$ end of the $\mathrm{SH} 3$ domain region was cloned using 5' -poly-A-tailed random-primed cDNA, an oligo-dT primer, and a specific reverse primer in the $5^{\prime}$ end of the known sequence.

In addition, a random-primed $\lambda$-ZAP cDNA library from lamprey brain mRNA was screened using standard methods (Sambrook et al., 1989). A probe was generated by restriction digestion of the subcloned band from the initial PCR, labeled with $\left[{ }^{32} \mathrm{P}\right] \mathrm{dCTP}$ using the ReadyTo-Go DNA Labeling Beads (GE Healthcare) and purified with a ProbeQuant G-50 Micro Column (GE Healthcare). Positive clones were sequenced.

Glutathione $S$-transferase (GST)-fusion protein constructs of the lamprey SH3 domains [A, amino acids 740-806; B, 913-972; C, 1002-1060; D, 1073-1138; E, 1154-1214; A-C, 762-1064; amino acid numbering of lamprey intersectin here corresponds to that of human intersectin $1 \mathrm{~L}$; GenBank accession number NP003015 (see also Fig. 1A)] were generated, using the pGEX-6P-2 vector (GE Healthcare). The numbering of the Drosophila Dap160 aa sequence in Figure $1 A$ is shown according to accession number AAC39138. The accession number of lamprey intersectin is EF134956.

Antibodies. Polyclonal antibodies were raised in rabbit against GSTfusion proteins of lamprey SH3 domains A-C (LIS-AC; corresponding to amino acids 762-1064 in human intersectin 1L) (see Fig. $1 A$ ) and SH3 domains C-E (LIS-CE; corresponding to amino acids 1034-1173 in human intersectin 1L) (see Fig. 1A). The antibodies were purified on protein A Sepharose (GE Healthcare) and affinity purified on a Hi-Trap column (GE Healthcare) with the antigen covalently coupled. Nonspecific rabbit IgGs were used in control experiments. Antibodies raised against Xenopus and rat intersectin EH domains (Hussain et al., 1999; Okamoto et al., 1999) were used for detection of intersectin. Dynamin was detected using the DG-1 (Grabs et al., 1997) and LD-1 (Evergren et al., 2004a) antibodies. D domain antibodies were used to detect lamprey synapsin (Bloom et al., 2003), and amphiphysin was detected using lamprey SH3 domain antibodies (Evergren et al., 2004b). The synaptojanin and Eps15 antibodies have been described previously (Gad et al., 2000; Kent et al., 2002). Synapsin E-domain antibodies (Pieribone et al., 1995) were used in microinjection experiments.

Affinity chromatography of tissue extracts and immunoprecipitation experiments. Intersectin antibodies were coupled to protein A Sepharose (GE Healthcare), and GST-fusion proteins were coupled to glutathione Sepharose (GE Healthcare) and incubated with a $10 \%$ lamprey brain detergent extract (Gad et al., 2000) in buffer A (10 mM HEPES buffer, $\mathrm{pH}$
7.4, containing $100 \mathrm{~mm} \mathrm{KCl,} 2 \mathrm{~mm} \mathrm{MgCl}_{2}$, and 1\% Triton X-100) plus protease inhibitors or only with buffer A for $2 \mathrm{~h}$ at $4^{\circ} \mathrm{C}$ on a rotating wheel. Samples were washed three times with buffer A with $1 \%$ Triton X-100 and three times with buffer A without Triton X-100, eluted with sample buffer, and analyzed by SDS-PAGE.

Microinjection experiments. Dissection of the trunk region of the lamprey spinal cord, microinjection procedures, stimulation, and fixation were performed as described previously (Gad et al., 2000). Animals were treated according to the Swedish Animal Welfare Act (SFS 1988:534), as approved by the Local Animal Research Committee of Stockholm. All efforts were made to minimize animal suffering and to reduce the number of animals used. Giant axons were stimulated at $5 \mathrm{~Hz}$ using extracellular electrodes (30 min; $\sim 9000$ action potentials). The effects described in this study were detectable even for stimulation at $0.2 \mathrm{~Hz}$ (30 min; 360 action potentials; data not shown). Naturally, fewer intermediates were observed around synapses stimulated at $0.2 \mathrm{~Hz}$, and the statistical analysis became very complex, because it required a quantitative analysis of hundreds of sections. Stimulation at $20 \mathrm{~Hz}$ was accomplished with intracellular electrodes. Action potentials in giant axons were monitored with an extracellular suction electrode placed at the caudal part of the preparation. Axons referred to as nonstimulated controls were either adjacent to axons stimulated intracellularly or from a specimen left at rest in a low $\mathrm{Ca}^{2+}$ Ringer's solution for 45-90 min. Microinjections of fluorescent reagents were monitored with a CCD camera (Princeton Instruments, Trenton, NJ) connected to a fluorescence microscope and a Nikon (Tokyo, Japan) D-eclipse C1 confocal microscope using a $40 \times$ waterimmersion objective (numerical aperture, 0.80 ). Confocal images were analyzed using NIH ImageJ software (http://rsb.info.nih.gov/ij/).

The antibodies and GST-fusion proteins used in microinjection experiments were labeled with Alexa-602, Alexa-594 (Invitrogen), or Cy5 (GE Healthcare) according to the manufacturer's instructions. PhalloidinAlexa-488 was purchased from Invitrogen. GTP $\gamma S$ (Roche Diagnostics, Indianapolis, IN) was diluted in Texas Red dextran (molecular weight, 3000 ; Invitrogen) to a final concentration of $10 \mathrm{~mm}$.

Spinal cords were fixed during stimulation in 3\% glutaraldehyde $/ 0.5 \%$ paraformaldehyde $/ 4 \%$ tannic acid in $0.1 \mathrm{M}$ cacodylate buffer, $\mathrm{pH} 7.4$, for $1 \mathrm{~h}$, followed by the same fixative without tannic acid for an additional $3 \mathrm{~h}$. After postfixation in $1 \%$ osmium tetroxide for $1 \mathrm{~h}$ and dehydration in alcohol, the specimens were embedded in Durcupan ACM (Fluka, Saint Quentin Fallavier, France). Serial ultrathin sections were cut with a diamond knife and viewed at $80 \mathrm{kV}$ in a Tecnai 12 or a Philips CM12 electron microscope (FEI, Ekerö, Sweden).

Effects of microinjections were analyzed in 20-60 synapses cut in serial ultrathin sections at various distances from microinjection sites (i.e., different concentrations). All described effects were reproduced in at least two independent preparations in which three to six axons were microinjected. The number of synaptic vesicles and coated pits and the membrane length of invaginations in the endocytic zone in antibody injection experiments were determined from middle sections of at least five serially cut synapses. Because the number of synaptic vesicles in the cluster is correlated to the length of the active zone in the reticulospinal synapse, the values for number of synaptic vesicles and coated pits were normalized to the length of the active zone (Gustafsson et al., 2002). The length of endocytic zone membrane invaginations in the axoplasm was measured in a $5 \times 3.5 \mu \mathrm{m}$ area above the active zone using NIH ImageJ software. In addition, the area of membrane invaginations was calculated in five injected synapses stimulated at $5 \mathrm{~Hz}$. The area of membrane folds was correlated to the expected membrane area of fused vesicles. The number of fused vesicles was estimated from the reduction of vesicles in a middle section, which correlates with the total number of vesicles in the synapse (Gustafsson et al., 2002).

Postembedding immunogold labeling of giant reticulospinal synapses. An unstimulated lamprey spinal cord was dissected out and fixed in $4 \%$ paraformaldehyde $/ 0.5 \%$ glutaraldehyde $/ 4 \%$ tannic acid in $0.1 \mathrm{M}$ cacodylate buffer, $\mathrm{pH} 7.4$, for $1 \mathrm{~h}$ at $4^{\circ} \mathrm{C}$ and then for $3 \mathrm{~h}$ in fixative without tannic acid. Specimens were stained en bloc with $2 \%$ uranyl acetate, dehydrated in graded ethanol series, and embedded at $-25^{\circ} \mathrm{C}$ in LR Gold resin (Fluka). Serial ultrathin sections were collected on nickel mesh grids and incubated overnight at $4^{\circ} \mathrm{C}$ with primary antibodies (LIS-AC 
A

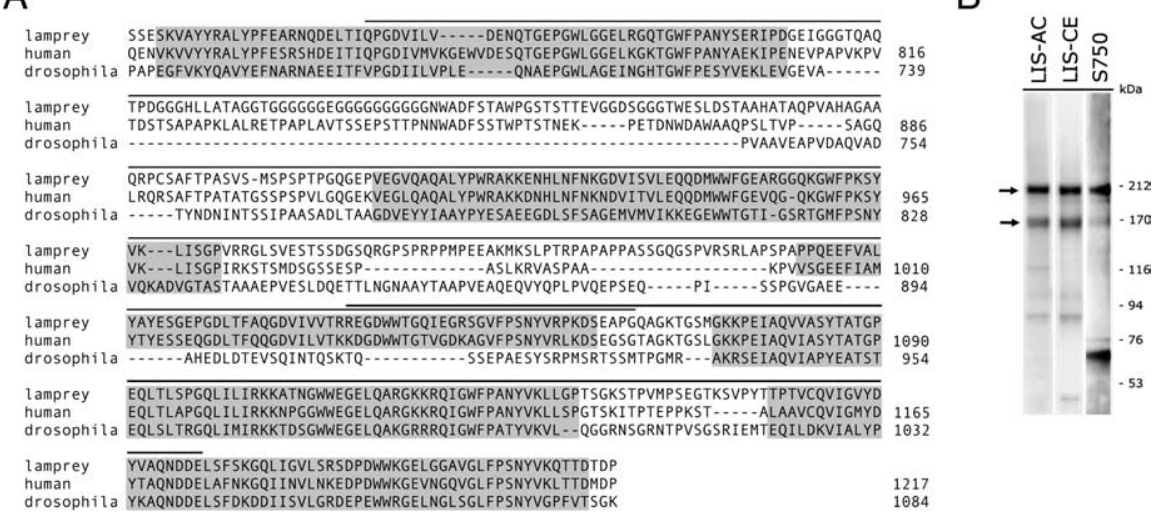

C

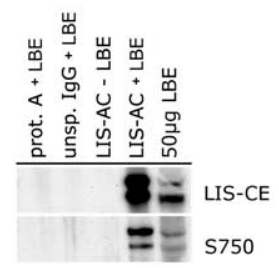

D

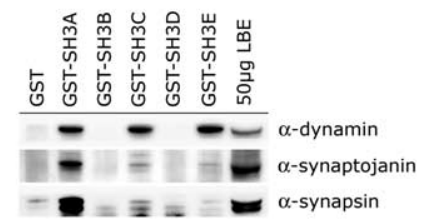

E

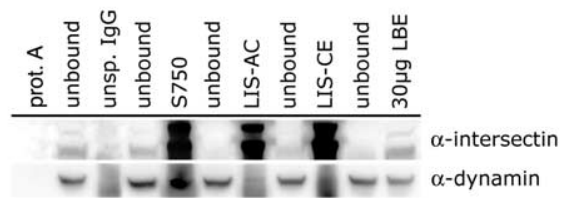

Figure 1. Identification of lamprey intersectin and its SH3 domain interactions. $A$, Alignment of lamprey intersectin, human intersectin 1L, and Drosophila Dap160. The gray boxes indicate SH3 domains A, B, C, D, and E in sequential order. The black lines mark the sequences used for raising the LIS-AC and LIS-CE antibodies. $\boldsymbol{B}$, Protein extracts from lamprey brain analyzed by SDS-PAGE (3-8\% gradient gel) and Western blot using LIS-AC, LIS-CE, and rat intersectin EH domain antibodies (S750). Arrows indicate bands presumed to correspond to the long and short isoforms of intersectin. $\boldsymbol{C}$, Immunoprecipitates from lamprey brain extracts (LBEs) prepared using LIS-AC antibodies. Intersectin was efficiently immunoprecipitated from LBE as shown by Western blots using LIS-CE and rat EH domain antibodies (S750). Protein (prot.) A Sepharose and nonspecific (unsp.) lgGs were used as controls. D, Affinity purification from LBE showing interactions of intersectin SH3 domains fused to GST with dynamin, synaptojanin, and synapsin. GST alone was used as control. $\boldsymbol{E}$, Western blot analysis of immunoprecipitates showing inhibition of the binding of dynamin to intersectin by LIS-AC and LIS-CE antibodies but not by S750 EH domain antibodies. Note that dynamin remained in the unbound, intersectin-depleted fraction of LIS-AC and LIS-CE immunoprecipitates. Nonspecific rabbit lgGs were used as control.

antibodies, $0.03 \mathrm{mg} / \mathrm{ml}$; DG-1 antibodies, $0.01 \mathrm{mg} / \mathrm{ml}$ ) diluted in $1 \%$ human serum albumin $/ 5 \%$ bovine serum albumin in Tris-PBS (TPBS), $\mathrm{pH}$ 7.4. Secondary antibodies conjugated to $5 \mathrm{~nm}$ colloidal gold (GE Healthcare) were used at a dilution of 1:25. Gold particles were enhanced using the IntenSE Silver enhancement kit (GE Healthcare). Sections were counterstained with uranyl acetate and lead citrate and examined in a Tecnai 12 electron microscope. Labeling experiments, in which primary antibodies were omitted, did not produce any specific labeling. The number of particles was quantified in selected regions, and the density of gold particles per square micrometer was calculated. The synaptic vesicle cluster was defined as a region containing synaptic vesicles clustered at an active zone. The periactive zone was defined as a presynaptic area $(0.5 \times$ $0.5 \mu \mathrm{m}$ ) lateral to the active zone, and the axoplasmic matrix was defined as an area $(0.5 \times 0.5 \mu \mathrm{m})>0.5 \mu \mathrm{m}$ from the synaptic vesicle cluster.

Preembedding immunocytochemistry for lamprey preparations. Lamprey spinal cords were incubated in either low $\mathrm{Ca}^{2+}$ or high $\mathrm{K}^{+}$Ringer's solution at $4.0^{\circ} \mathrm{C}$ for $20 \mathrm{~min}$ or stimulated electrically at $5 \mathrm{~Hz}$ for $30 \mathrm{~min}$, fixed in 3\% paraformaldehyde $/ 0.5 \%$ glutaraldehyde in $0.1 \mathrm{M}$ phosphate buffer, $\mathrm{pH} 7.4$, for $4 \mathrm{~h}$. Longitudinal sections were cut in a vibratome to open up giant reticulospinal axons and thereby provide access for antibodies. Microinjected specimens were also cut transversally at the site of injection (supplemental Fig. 6, available at www.jneurosci.org as supplemental material). The labeling procedure was performed as described previously (Evergren et al., 2004a). Briefly, specimens were incubated with primary antibodies (LIS-AC and LD-1 antibodies, $0.03 \mathrm{mg} /$ $\mathrm{ml}$; amphiphysin-SH3 antibodies, $0.13 \mathrm{mg} / \mathrm{ml}$ ) diluted in $1 \%$ human serum albumin in TPBS overnight at $4^{\circ} \mathrm{C}$ on a shaker. After incubation with secondary antibodies (5-nm-goldconjugated diluted 1:50; GE Healthcare), the specimens were postfixed in 3\% glutaraldehyde in $0.1 \mathrm{~m}$ phosphate buffer, $\mathrm{pH} 7.4$, for $1 \mathrm{~h}$, and in $1 \%$ osmium tetroxide for $1 \mathrm{~h}$. Sections were stained en bloc with uranyl acetate and embedded in Durcupan ACM (Fluka). Ultrathin sections were counterstained with uranyl acetate and lead citrate and examined in a Tecnai 12 microscope. Quantification of immunogold labeling at constricted collared clathrin-coated intermediates was performed as described in the legend to supplemental Figure 7 (available at www.jneurosci.org as supplemental material). Omission of primary antibodies did not produce any labeling. The periactive zone was defined as above.

\section{Results}

Characterization of lamprey intersectin-dynamin interactions

By screening a randomly primed cDNA library from lamprey brain using degenerate and specific primers, we acquired a sequence corresponding to the lamprey intersectin SH3 domains A-E. The cloned sequence had $79 \%$ similarity (58\% identity) to the $\mathrm{SH} 3$ domain region of human intersectin $1 \mathrm{~L}$ and $59 \%$ similarity to Drosophila Dap160 (Fig. 1A). The similarity of the lamprey sequence to human intersectin $2 \mathrm{~L}$ was $72 \%$.

GST-fusion proteins of SH3 domains $\mathrm{A}-\mathrm{C}$ and $\mathrm{C}-\mathrm{E}$ were expressed and used to generate antibodies (Fig. 1A). Long and short isoforms of mammalian and Xenopus intersectin migrate at 200 and $170 \mathrm{kDa}$ by SDS-PAGE, respectively (Hussain et al., 1999; Okamoto et al., 1999). The affinitypurified antibodies LIS-AC and LIS-CE recognized two bands of the expected molecular weight in Western blots of lamprey brain detergent extract (Fig. $1 \mathrm{~B}$ ). Bands of the same molecular weight were also detected by polyclonal antibodies raised against the EH domains of rat (S750) (Fig. $1 \mathrm{~B}$ ) and Xenopus intersectin, as well as by an antibody raised against the $\mathrm{SH} 3$ domains of rat intersectin (data not shown). To provide additional evidence that the antibodies recognize lamprey intersectin, we immunoprecipitated the protein from lamprey brain extract using LIS-AC antibodies and detected the precipitate using the antibodies LIS-CE and S750. Both antibodies recognized bands at 200 and $170 \mathrm{kDa}$ (Fig. $1 C)$. Intersectin could also be immunoprecipitated using the LIS-CE antibody (Fig. $1 E$ ). We thus conclude that the proteins identified by the LIS-AC and LIS-CE antibodies are the lamprey intersectin orthologs.

We next investigated whether lamprey intersectin interacts with dynamin as well as with other endocytic proteins via its $\mathrm{SH} 3$ domains. Interactions with synaptojanin and synapsin in addition to dynamin have been reported previously for mammalian and Drosophila intersectin/Dap160 (Roos and Kelly, 1998; 


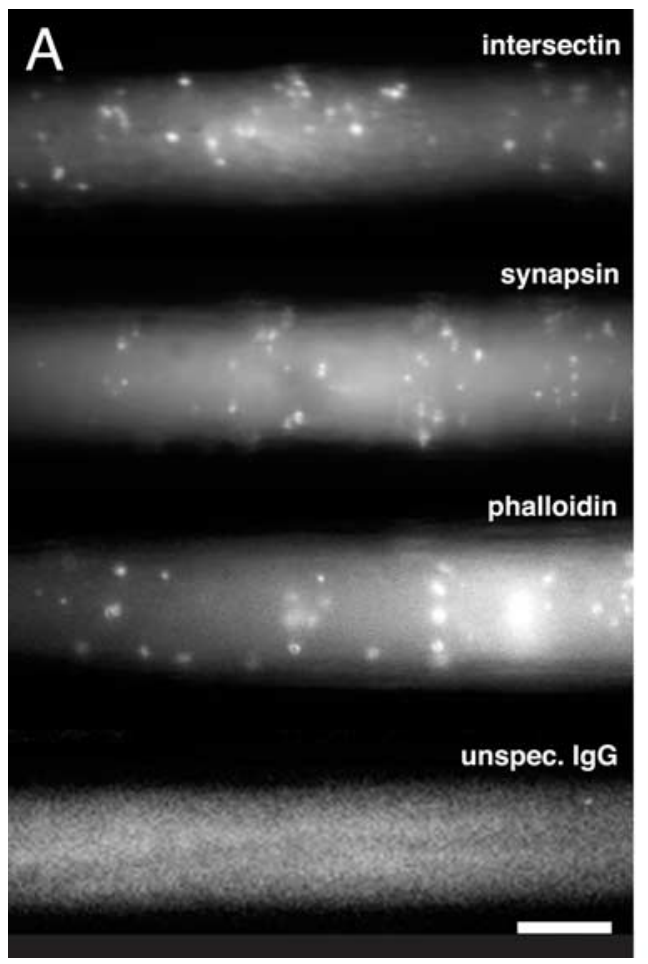

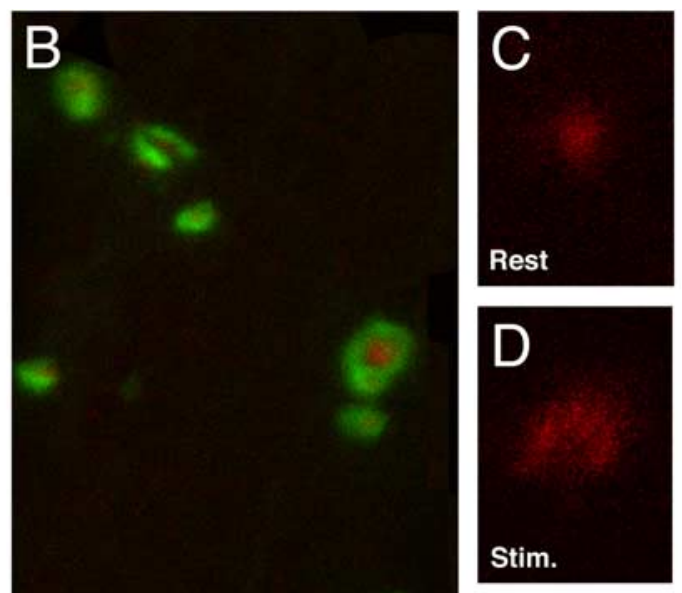

intersectin
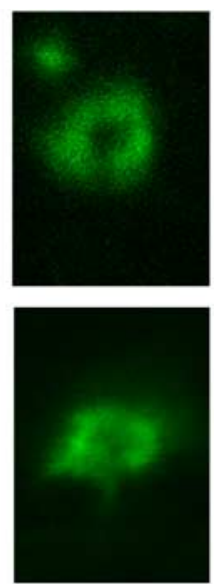

phalloidin
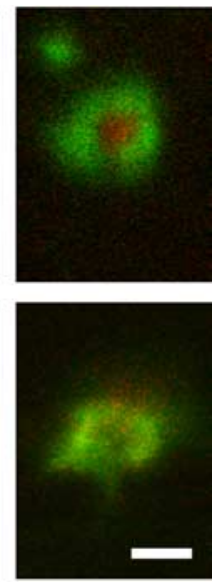

merge

Figure 2. Localization of intersectin in living lamprey reticulospinal axons. A, Microinjection of fluorescence-tagged intersectin LIS-AC antibodies, synapsin G304 antibodies, and phalloidin into living giant reticulospinal axons produced an accumulation of fluorescence in spots. Nonspecific (unspec.) rabbit lgG did not produce an accumulation of fluorescence. $\boldsymbol{B}-\boldsymbol{D}$, Confocal images of reticulospinal synapses double injected with LIS-AC antibodies (red) and phalloidin (green). Images were acquired in axons at rest $(\boldsymbol{B}, \boldsymbol{C})$ and after 20 min of stimulation at $5 \mathrm{~Hz}(\boldsymbol{D})$. $\boldsymbol{B}$, The arrow points at the synapse shown at higher magnification in $C$. The ratio between intersectin immunofluorescence in the active zone and the periactive zone in resting and stimulated (Stim.) synapses $\left(F \mid F_{\text {periactive zone }}\right)$ is statistically significant $(p<0.0001$; two-tailed Student's $t$ test). The periactive zone area was defined as the area covered by the phalloidin ring. Scale bars: $\boldsymbol{A}, 50 \mu \mathrm{m} ; \boldsymbol{B}$, $4 \mu \mathrm{m}$; (in D) $C, D, 2 \mu \mathrm{m}$.

Okamoto et al., 1999; Zamanian et al., 2003). GST-fusion proteins of single $\mathrm{SH} 3$ domains of lamprey intersectin were used to affinity purify binding partners from lamprey brain extract. Bound material was analyzed by SDS-PAGE and Western blot (Fig. 1D). Dynamin was found to interact with the $\mathrm{SH} 3$ domains A, C, and E. Synaptojanin and synapsin bound mainly to SH3A. Thus, our data indicate that the interactions with dynamin, synaptojanin, and synapsin are conserved in lamprey.

The goal of our study was to clarify the role of intersectindynamin interactions in the synapse by using antibodies to acutely perturb these interactions. We therefore investigated whether the antibodies were able to inhibit the binding of dynamin to intersectin. Intersectin was immunoprecipitated using either LIS-AC or LIS-CE antibodies. "Bound" and "unbound" fractions were analyzed by Western blot (Fig. $1 E$ ). Both antibodies efficiently precipitated intersectin, depleting it from the extract. However, only a small amount of dynamin was detected in the bound fractions, indicating that the antibodies were blocking the binding sites for dynamin efficiently (Fig. 1E). Eps15, an endocytic protein that binds to the intersectin coiled-coil region (Okamoto et al., 1999; Sengar et al., 1999), was, however, efficiently coprecipitated (data not shown). Immunoprecipitation of intersectin using the EH domain antibody S750 efficiently coimmunoprecipitated dynamin. We thus conclude that the lamprey intersectin antibodies occupy the binding sites for dynamin.

\section{Localization of intersectin in living synapses in situ}

Previous studies in Drosophila NMJs have demonstrated that dynamin redistributes to endocytic sites during synaptic activity (Estes et al., 1996), whereas intersectin is stably localized to the endocytic zone (Roos and Kelly, 1998, 1999). To investigate whether this is also true for central vertebrate synapses, Alexatagged intersectin antibodies were microinjected into living reticulospinal axons. This resulted in an accumulation of fluorescence at spots on the axonal surface (Fig. 2A). Concentration of the labeling was facilitated by the induction of action potentials in the axons. An accumulation of fluorescence in spots was also observed after microinjections of antibodies against the synaptic vesicle proteins synapsin (Fig. 2A) and synaptotagmin (Pieribone et al., 1995), as well as phalloidin (Fig. 2A), which labels filamentous actin in the periactive zone of synapses (Shupliakov et al., 2002). Nonspecific IgGs failed to accumulate in spots (Fig. $2 A$ ). This strongly indicated that the intersectin antibodies accumulated at synaptic regions.

Even when using a CCD camera (Fig. 2A), it was evident that the spots of fluorescence induced by the reagents had different appearances. To obtain more detailed information on the localization of intersectin, we used confocal microscopy. Axons were microinjected with Alexa-594-tagged intersectin antibodies, which was followed by microinjection of Alexa-488-phalloidin. This resulted in an accumulation of both reagents at synaptic regions (Fig. $2 B-D$ ). Figure $2 B$ shows a low-power image of a reticulospinal axon microinjected under resting conditions. Analysis of the labeling pattern revealed that intersectin antibodies accumulated in a spot, whereas the majority of the periactive zone marker phalloidin surrounded this site (Fig. 2C). A merge of the two images placed the intersectin labeling in the middle of the "phalloidin ring," corresponding to the localization of the synaptic vesicle cluster (Shupliakov et al., 2002). Figure $2 D$ shows an image of a synapse acquired during stimulation at $5 \mathrm{~Hz}$. Under 


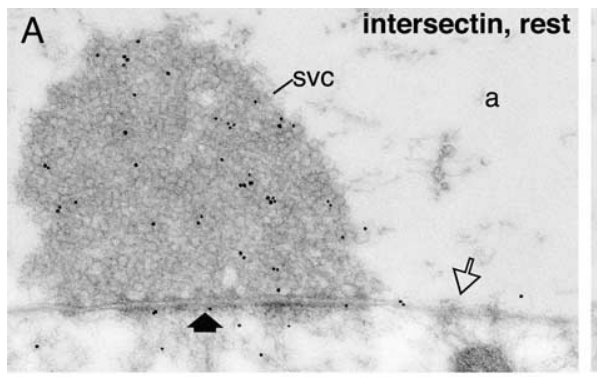

B
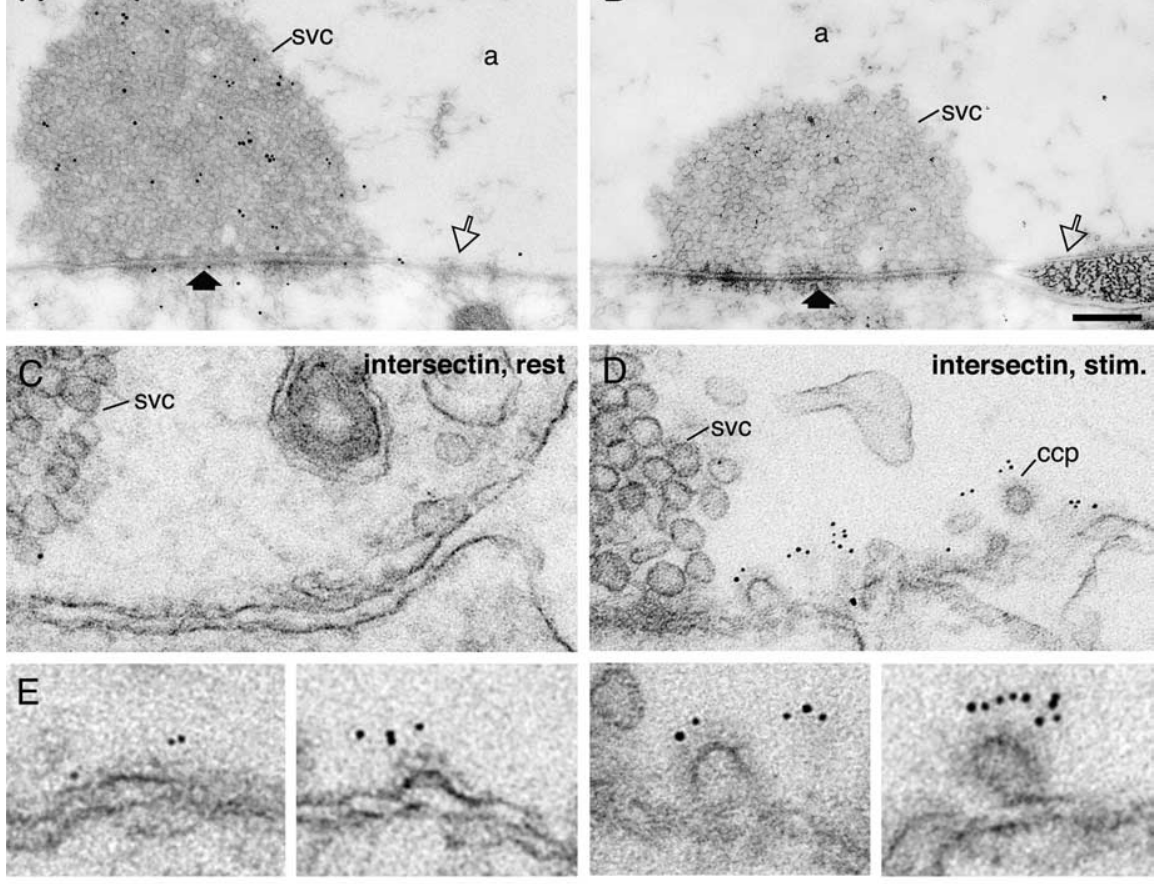

$\mathrm{F}$
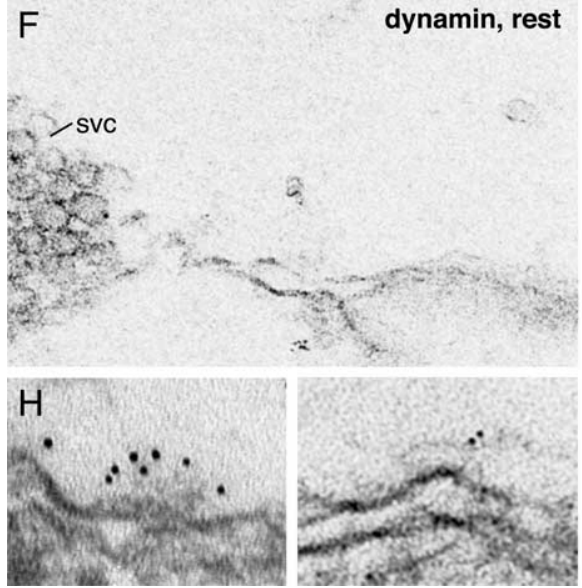

intersectin, stim.
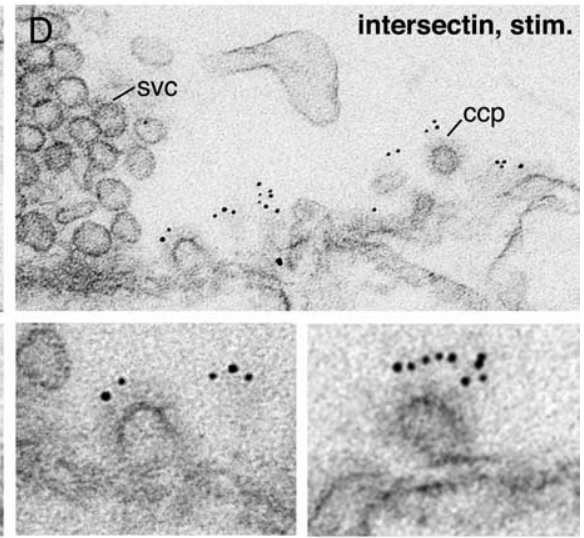

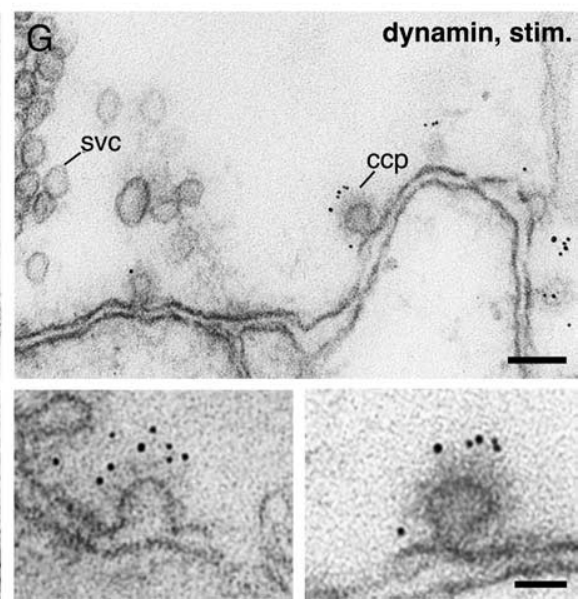

Figure 3. Redistribution of intersectin immunoreactivity in the giant reticulospinal synapse in response to stimulation. $\boldsymbol{A}, \boldsymbol{B}$ Electron micrographs of reticulospinal synapses fixed at rest and labeled with LIS-AC $(\boldsymbol{A})$ and dynamin $(\boldsymbol{B})$ antibodies using postembedding immunogold technique. The filled thick arrows mark the active zone. The open arrows indicate the periactive zone. $\boldsymbol{C}, \boldsymbol{D}, \boldsymbol{F}, \boldsymbol{G}$, Periactive zones of reticulospinal synapses fixed at rest $(\boldsymbol{C}, \boldsymbol{F})$ and during $\mathrm{K}^{+}$stimulation $(\boldsymbol{D}, \boldsymbol{G})$ labeled with the LIS-AC $(\boldsymbol{C}, \boldsymbol{D})$ and dynamin $(\boldsymbol{F}, \boldsymbol{G})$ antibodies using a preembedding immunogold protocol. Note an increase in the number of gold particles in the periactive zones of stimulated compared with resting synapses. $\boldsymbol{E}, \boldsymbol{H}$, Electron micrographs showing association of intersectin $(\boldsymbol{E})$ and dynamin $(\boldsymbol{H})$ immunoreactivity with clathrin-coated intermediates at different stages. a, Axoplasmic matrix; svc, synaptic vesicle cluster; ccp, clathrin-coated pit; stim., stimulated. Scale bars: (in $\boldsymbol{B}$ ) $\boldsymbol{A}, \boldsymbol{B}, 0.4 \mu \mathrm{m}$; (in $\boldsymbol{G}$ ) $\boldsymbol{C}, \boldsymbol{D}, \boldsymbol{F}, \boldsymbol{G}, 0.1 \mu \mathrm{m}$; (in H) $\boldsymbol{E}, \boldsymbol{H}, 0.05 \mu \mathrm{m}$.

these conditions, the intersectin antibodies were dispersed over a larger area of the synapse, and colocalized with phalloidin rings (Fig. 2D). These results indicate that intersectin relocates to the periactive zone during synaptic activity in a living vertebrate synapse. To investigate this observation further, we studied the localization of intersectin in the periactive zone at the ultrastructural level.

\section{Subcellular localization of intersectin and dynamin in the giant reticulospinal synapse}

To localize intersectin at the ultrastructural level, we first used the postembedding immunogold technique, which provides anti- bodies equal access to epitopes exposed on the surface of a section (Ottersen, 1989). In agreement with light microscopic observations (Fig. 2C), periactive zones in synapses fixed at rest contained only a few gold particles when labeled with intersectin antibodies (Fig. 3A). Immunogold particles were predominantly associated with synaptic vesicle clusters (Fig. 3A) (Evergren et al., 2006). The density of gold particles over this synaptic region (21.6 \pm 5.6 particles $/ \mu \mathrm{m}^{2} ; n=14$; mean \pm SEM) was 20 times higher than in the axoplasmic matrix $\left(1.4 \pm 0.5\right.$ particles $/ \mu \mathrm{m}^{2} ; n=13$; mean \pm SEM; $p<0.0001$; two-tailed Student's $t$ test). The level of labeling in the periactive zone area (1.8 \pm 1.0 particles/ $\mu \mathrm{m}^{2} ; n=21$; mean \pm SEM) was not significantly different from the labeling over the axoplasmic matrix $(p>0.05$; twotailed Student's $t$ test). Labeling for dynamin showed a distribution pattern similar to that of intersectin (Fig. 3B). Gold particles were predominantly accumulated over the synaptic vesicle cluster $\left(20.2 \pm 4.1\right.$ particles $/ \mu \mathrm{m}^{2} ; n=16$; mean \pm SEM), compared with the axoplasmic matrix (1.5 \pm 0.6 particles $/ \mu \mathrm{m}^{2} ; n=16$; mean \pm SEM; $p<0.0001$; two-tailed Student's $t$ test) or the periactive zone (1.0 \pm 0.3 particles $/ \mu \mathrm{m}^{2} ; n=16$; mean $\pm \mathrm{SEM} ; p<$ 0.0001; two-tailed Student's $t$ test).

To achieve a higher labeling efficiency at periactive zones, we used a preembedding immunogold technique (Evergren et al., 2004a). No clear association of gold particles with this region in synapses at rest was detected for intersectin (Fig. 3C) (6.7 particles $/ \mu \mathrm{m}^{2}$; mean $\left.\pm \mathrm{SEM} ; n=14\right)$. However, strong labeling of periactive zones was observed in synapses stimulated with high $\mathrm{K}^{+}$for $20 \mathrm{~min}$ (Fig. 3D) (54.7 \pm 7.0 particles $/ \mu \mathrm{m}^{2}$; mean \pm SEM, $\left.n=14\right)$. The density of gold particles was increased more than eightfold compared with resting synapses $(p<0.0001$; two-tailed Student's $t$ test). Gold particles were found predominantly on endocytic intermediates from early to late stages and were associated with the coat region (Fig. $3 D, E$ ). A similar labeling pattern was obtained with LIS-AC and LIS-CE intersectin antibodies. Similar to intersectin, the dynamin immunolabeling was also associated with clathrin-coated intermediates in the periactive zone in stimulated synapses at different stages (Fig. $3 G, H$ ). The labeling in the periactive zone was significantly increased in stimulated synapses (34.6 \pm 3.2 particles $/ \mu \mathrm{m}^{2}$; mean \pm SEM; $\left.n=8\right)$ compared with resting terminals (Fig. $3 F, G)\left(0.6 \pm 0.4\right.$ particles $/ \mu \mathrm{m}^{2}$; mean \pm SEM; $n=8 ; p<0.0001$; two-tailed Student's $t$ test). Together, these results show that intersectin and its binding partner dynamin are redistributed after stimulation from the synaptic vesicle cluster to the periactive zone and that they are associated with endocytic intermediates in synapses from early stages on. 

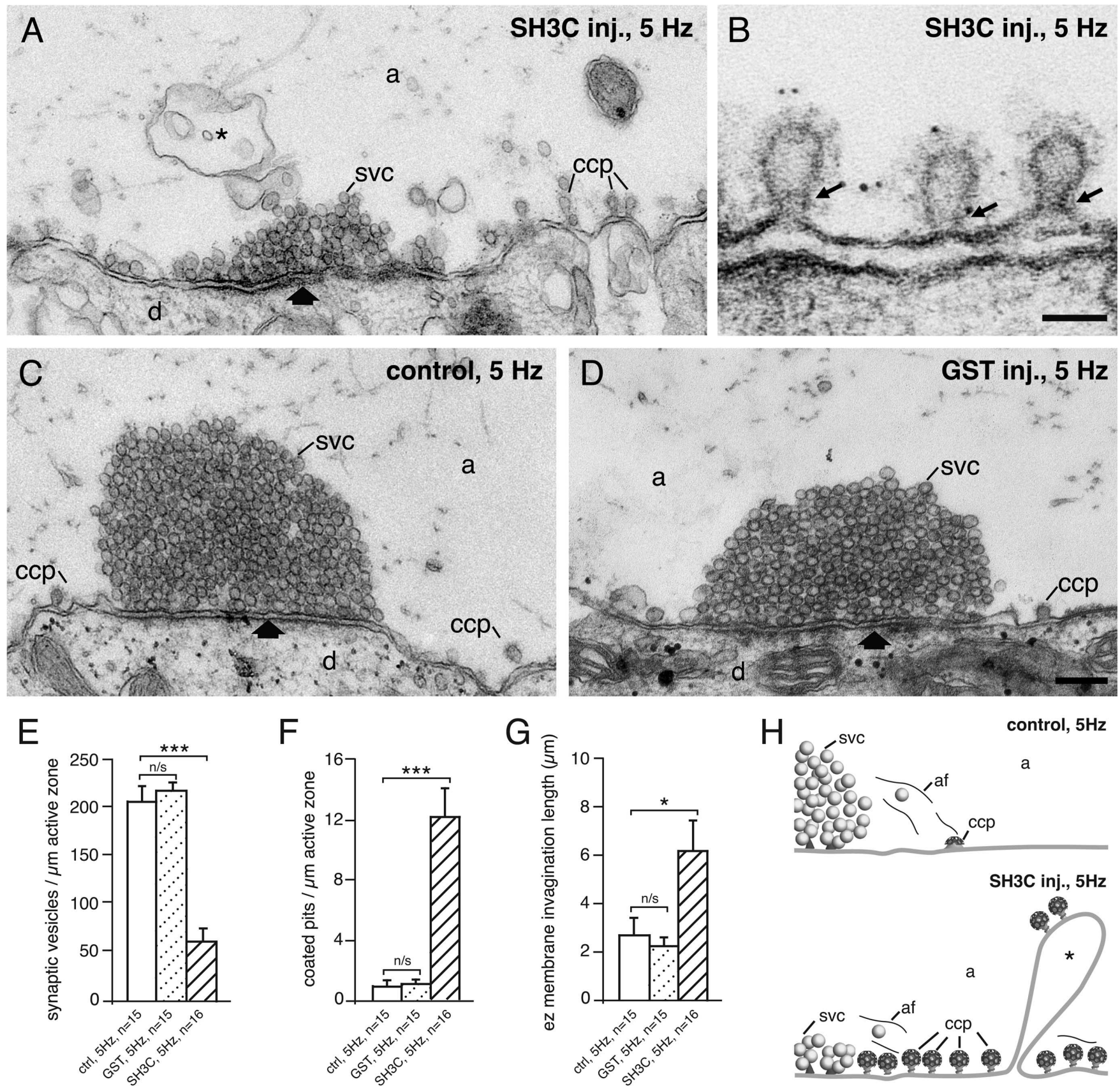

control, $5 \mathrm{~Hz}$

a

Figure 4. Microinjection of intersectin GST-SH3C domain inhibits synaptic vesicle recycling. $A, B$, Electron micrographs of reticulospinal synapses microinjected with the GST-SH3C domain of intersectin and stimulated at $5 \mathrm{~Hz}$ for $30 \mathrm{~min}$. Note the reduction of vesicles clustered at active zones and an accumulation of clathrin-coated pits and membrane invaginations (asterisk) compared with an uninjected synapse (C).B, Electron micrograph showing constricted collared clathrin-coated pits. The thin arrows point to constricted necks with collars. In this experiment, the synapse was also labeled with amphiphysin antibodies using the immunogold technique (Fig. 7). C, Electron micrograph of an uninjected control synapse stimulated at $5 \mathrm{~Hz}$. D, Electron micrograph showing a synapse microinjected with GST. $\boldsymbol{E}$, Bar graph showing the mean relative size of the synaptic vesicle pool in uninjected synapses stimulated at $5 \mathrm{~Hz}$ compared with synapses microinjected with GST or GST-SH3C. F, Changes in the average number of coated intermediates per synapse induced by GST-SH3C domain injection in stimulated synapses compared with uninjected and GST-injected synapses. $\mathbf{G}$, Bar graph illustrating the average length of membrane structures at the endocytic zone (ez). $\boldsymbol{H}$, Schematics summarizing the observed morphological effects. Error bars represent the SE for each group. $n$ represents the number of middle sections analyzed in each group. ${ }^{*} p<0.05 ;{ }^{* * *} p<0.0001$; two-tailed Student'st test. Designations are the same as in Figure 3. d, Dendrite; af, actin filaments; ctrl, control; inj., injected; $\mathrm{n} / \mathrm{s}$, not significant. Scale bars: (in D) $\boldsymbol{A}, \boldsymbol{C}, \boldsymbol{D}, 0.2 \mu \mathrm{m} ; \boldsymbol{B}, 0.05 \mu \mathrm{m}$.

\section{Acute perturbation of intersectin-dynamin interactions} disrupts synaptic vesicle membrane recycling

Previous studies in non-neuronal cells have demonstrated that the overexpression of $\mathrm{SH} 3$ domains efficiently inhibits clathrinmediated endocytosis (Simpson et al., 1999). To test whether the blockade of intersectin-binding sites on dynamin may negatively affect endocytosis in a living reticulospinal synapse, GST-SH3C domain was microinjected into reticulospinal axons and stimu- lated to induce synaptic vesicle recycling at a physiological rate (5 $\mathrm{Hz}$ ) (Deliagina and Fagerstedt, 2000) and then analyzed in serial ultrathin sections (supplemental Fig. $1 B$, available at www. jneurosci.org as supplemental material). The domain induced a significant reduction in the size of the synaptic vesicle pool compared with uninjected control synapses (Fig. $4 A, C, E)(p<$ 0.0001; two-tailed Student's $t$ test). An increase in the number of constricted clathrin-coated pits with electron-dense collars (Fig. 

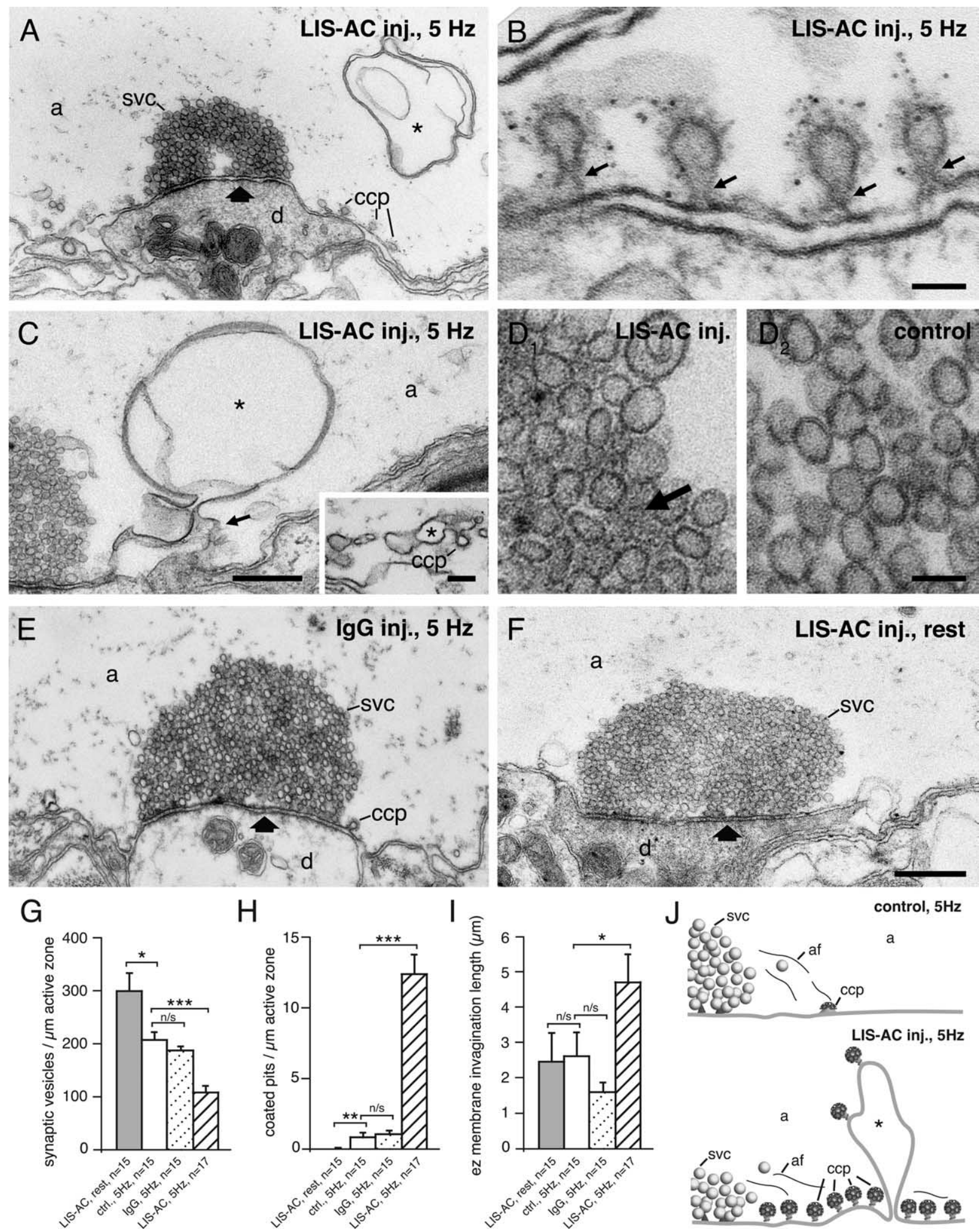

Figure 5. Effects of acute perturbation of intersectin $\mathrm{SH} 3$ domain interactions by antibodies. $\mathbf{A - D}$, Electron micrographs of synapses in reticulospinal axons stimulated at $5 \mathrm{~Hz}$ for $30 \mathrm{~min}$ after microinjection of LIS-AC antibodies. Note the accumulation of constricted coated pits $(\boldsymbol{A}, \boldsymbol{B})$ and membrane infolds $(\boldsymbol{A}, \boldsymbol{C})$ at the periactive zone. Constricted coated pits in $\boldsymbol{B}$ were also labeled with dynamin antibodies (LD-1; Fig. 7). C, Electron micrograph of a membrane infold connected to the plasma membrane as revealed by serial section analysis. The inset shows a membrane infold with a budding clathrin-coated pit. $\boldsymbol{D}$, Electron micrographs showing synaptic vesicle clusters from an axon microinjected with LIS-AC $\left(\boldsymbol{D}_{1}\right)$ and an uninjected control axon $\left(\boldsymbol{D}_{2}\right)$. Note a dense cytomatrix between synaptic vesicles in $\boldsymbol{D}_{\boldsymbol{1}}$ (arrow). $\boldsymbol{E}$, A synapse from an axon microinjected with nonspecific lgG and stimulated at $5 \mathrm{~Hz}$. $\boldsymbol{F}$, Electron micrograph of a resting reticulospinal synapse after LIS-AC antibody microinjection. The average number of synaptic vesicles in microinjected synapses was not significantly different from uninjected resting synapses ( $p>0.05$; two-tailed Student's $t$ test; $n=14) . \mathbf{G}$, Bar graph showing the average relative reduction in the number of synaptic vesicles in synapses injected with intersectin antibodies compared with control synapses stimulated at $5 \mathrm{~Hz}$. $\boldsymbol{H}$, Changes in the average number of coated intermediates per synapse induced by antibody injection in stimulated synapses. $\boldsymbol{I}$, Bar graph illustrating the average length of membrane structures at endocytic zones. These membrane structures most likely derive from synaptic vesicles, because a correlation between the membrane area of invaginations and the membrane area of fused synaptic vesicles was found in synapses microinjected with LIS-AC antibodies stimulated at $5 \mathrm{~Hz}\left(r^{2}=0.7 ; 6\right.$ synapses were analyzed in serial sections). J, Schematics summarizing the observed morphological effects. ${ }^{* *} p<0.01$; two-tailed Student's t test. Designations are the same as in Figures 3 and 4. Scale bars: (in $\boldsymbol{F}$ ) $\boldsymbol{A}, \boldsymbol{E}, \boldsymbol{F}, 0.5 \mu \mathrm{m} ; \boldsymbol{B}, 0.05 \mu \mathrm{m} ; \boldsymbol{C}, 0.3 \mu \mathrm{m} ; \boldsymbol{C}$, inset, $0.1 \mu \mathrm{m} ; \boldsymbol{D}, 0.05 \mu \mathrm{m}$. 
$4 A-C, F)(p<0.0001$; two-tailed Student's $t$ test) and an accumulation of membrane infolds at periactive zones occurred (Fig. 4A, $C, G)(p<0.05$; twotailed Student's $t$ test), indicating that endocytosis was inhibited. The morphology of synapses injected with GST did not differ significantly from uninjected control synapses (Fig. $4 C-G)(p>0.05$; twotailed Student's $t$ test). GST-SH3B domain was used as a control, because it does not bind dynamin (Fig. 1D). It did not produce an accumulation of coated pits (supplemental Fig. 2A,D, available at www. jneurosci.org as supplemental material) ( $p>0.05$; two-tailed Student's $t$ test) or membrane invaginations (supplemental Fig. $2 A, E$, available at www.jneurosci.org as supplemental material) ( $p>0.05$; twotailed Student's $t$ test). Together, these data show that acute perturbation of dynamin function by intersectin SH3C domain inhibits synaptic vesicle recycling and interferes with the fission of vesicles from the plasma membrane (Fig. $4 H$, schematics).

To block intersectin SH3 domain interactions, LIS-AC antibodies were microinjected into living reticulospinal synapses. As in the case of the SH3C domain injection, a significant reduction in number of synaptic vesicles (Fig. 5G) $(p<0.0001$; two-tailed Student's $t$ test), an accumulation of clathrin-coated pits (Fig. $5 H)(p<0.0001$; two-tailed Student's $t$ test), and an increase in membrane folds occurred (Fig. 5I) $(p<0.05$; two-tailed Student's $t$ test) compared with uninjected synapses stimulated at $5 \mathrm{~Hz}$ (Figs. $4 C, 5 A-C$, schematics in 5J, supplemental Figs. 1, 5, available at www.jneurosci.org as supplemental material). Several control experiments confirmed that the effects of the antibodies on synaptic vesicle recycling were specific. First, they were not observed in synapses of axons microinjected with intersectin antibodies at rest (Fig. $5 F-I)(p>0.05$; two-tailed Student's $t$ test). Second, the induced defects were different compared with those produced by synapsin E-domain antibodies, which cause disruption of the distal pool of vesicles in the synaptic vesicle cluster (supplemental Fig. 5D, available at www.jneurosci.org as supplemental material) (Pieribone et al., 1995). Third, injection of nonspecific rabbit IgGs did not induce changes in the presynaptic membrane organization in the periactive zone (Fig. $5 E, G-I)(p>0.05$; two-tailed Student's $t$ test). In addition, antibodies raised against the $\mathrm{SH} 3$ domain of another endocytic protein, endophilin, induced numerous shallow coated pits, as we reported previously (Ringstad et al., 1999).

An electron-dense cytomatrix occurred within the pool of remaining vesicles exposed to the antibodies (Fig. 5D), suggesting that they interacted with intersectin in this region and formed a complex that was detectable in the electron microscope. The dense matrix did not block fusion of vesicles, because a full depletion of vesicles and large membrane folds occurred in synapses exposed to high-frequency stimulation (supplemental Fig. $5 A, B, E$, available at www.jneurosci.org as supplemental material).

Previous studies have demonstrated that an actin-rich cyto- matrix is present at the periactive zone (Shupliakov et al., 2002; Bloom et al., 2003). This cytomatrix is poorly preserved in osmicated material used for conventional electron microscopy. To test whether a disruption of the actin cytoskeleton might have occurred, microinjections of GST-SH3C domain and LIS-AC antibodies were followed by fluorescently labeled phalloidin. Contrary to the control synapses, in which phalloidin accumulated in ring-like structures, many of the phalloidin rings were fragmented in the axons injected with the reagents and had a larger diameter (supplemental Fig. 3, available at www.jneurosci.org as supplemental material) $(p<0.01$; two-tailed Student's $t$ test; $n=21)$.

Together, the results from domain and antibody injections allow us to conclude that acute perturbation of intersectin-dynamin interactions in a living vertebrate synapse perturbs the organization of the periactive zone and interferes with the recycling of synaptic vesicle membrane (Figs. $4 H$, 5J, schematics).

\section{Morphology of clathrin-coated pits and immunolocalization of dynamin after perturbation of intersectin-dynamin interactions}

The most striking effect of microinjections of intersectin domains and antibodies was a 13-fold increase in clathrin-coated pits compared with uninjected control synapses (Figs. 4F, 5H). The majority $(90 \%)$ of clathrin-coated pits were trapped at a stage of constriction and contained electron-dense collars (Fig. $6 A, B$ ), compared with $10 \%$ in uninjected control synapses (Fig. $6 A, B)$ (IgG, 2\%; GST, 3\%; SH3B, 3\%) (supplemental Figs. 2F, 4, available at www.jneurosci.org as supplemental material). To investigate whether this was caused by a perturbation of the dynamin-based fission mechanism, we first studied the endocytic 
intermediates induced by SH3C and LIS-AC antibody injections at high resolution. Interestingly, the collars observed in synapses exposed to GST-SH3C domain or LIS-AC antibodies (Fig. 6C,D) were thinner than those found on constricted coated pits in noninjected control axons or on intermediates trapped by the microinjection of GTP $\gamma \mathrm{S}$ (Fig. 6E,F), suggesting that some components in the fission complex might be missing. To investigate this further, dynamin and amphiphysin, two key components of the fission complex, were immunolocalized at these endocytic intermediates using preembedding immunocytochemistry in microinjected axons cut in two halves after fixation (Fig. 7, supplemental Fig. 6, available at www.jneurosci.org as supplemental material). A twofold reduction of dynamin labeling at the fission complex region of endocytic intermediates trapped by GST$\mathrm{SH} 3 \mathrm{C}$ was observed, compared with that of control (Fig. 7D) $(p<0.05$; two-tailed Student's $t$ test), whereas amphiphysin labeling was not significantly changed (Fig. $7 D)(p>0.05$; twotailed Student's $t$ test). This was not attributable to an overall reduction of dynamin recruitment to the endocytic zone, because the total dynamin labeling per coated pit was similar to the control (Fig. 7D) ( $p>0.05$; two-tailed Student's $t$ test). Surprisingly, a fourfold increase in labeling at the fission complex region of intermediates trapped by LIS-AC microinjection occurred (Fig. $7 D)(p<0.0001$; two-tailed Student's $t$ test), along with a small increase in amphiphysin labeling (Fig. 7D) $(p<0.01$; two-tailed Student's $t$ test). This was accompanied by an overall increase in dynamin labeling around coated pits (Fig. 7D) $(p<0.0001$; twotailed Student's $t$ test), demonstrating that more dynamin was detectable in the endocytic zone after intersectin antibody microinjection. There was no significant change in amphiphysin labeling per coated pit in these experiments compared with uninjected control (Fig. 7D) ( $p>0.05$; two-tailed Student's $t$ test). A dramatic increase in dynamin immunoreactivity around coated intermediates after perturbation of intersectin $\mathrm{SH} 3$ domain interactions indicates that intersectin negatively controls dynamin recruitment to the periactive zone (Fig. 8). This increase in dynamin level does not, however, lead to efficient fission. This further implies that a mechanism that actively directs dynamin to the neck region of the clathrin-coated pit may exist, which becomes inhibited when the intersectin-dynamin interaction is acutely perturbed.

\section{Discussion}

Previous studies in Drosophila have revealed an essential role for intersectin in the regulation of synaptic vesicle recycling. These studies suggested that it is an integral component of the periactive zone and that it functions as a molecular scaffold to concentrate endocytic proteins (Roos and Kelly, 1999; Koh et al., 2004; Marie et al., 2004). In agreement with this function, intersectin deletion mutants displayed a dramatic reduction in several proteins involved in clathrin-mediated endocytosis, including dynamin, endophilin, synaptojanin, and AP180 (adaptor protein 180) (Koh et al., 2004). Our present study shows that intersectin has a dynamic localization in the lamprey giant synapse and that its function is not restricted to the periactive zone. It relocates to endocytic sites after stimulation and is localized to the synaptic vesicle cluster at rest. Our data indicate that during its cycle, intersectin controls the function of its major binding partner, dynamin, at two different steps. First, it functions as a negative regulator of dynamin redistribution from the vesicle cluster to the periactive zone, and second, it may facilitate the function of dynamin during fission of clathrin-coated vesicles.

Intersectin and dynamin interact with each other in vitro and colocalize in the vesicle cluster at rest. This strongly suggests that they form a complex in this synaptic compartment (Fig. 8A). Imaging experiments show that intersectin antibodies specifically accumulate at vesicle clusters in living synapses at rest. We suggest that they efficiently compete with the binding to dynamin, in agreement with our in vitro experiments. This competition would cause a disruption of dynamin-intersectin interactions in the cluster, creating a pool of dynamin not bound to intersectin. A dramatic increase in dynamin immunoreactivity at periactive zones occurred after antibody microinjection, suggesting that this pool of dynamin is relocated to the periactive zone in a nonregulated manner. Together, these data indicate that intersectin negatively regulates dynamin redistribution to the periactive zone (Fig. $8 \mathrm{~B}$ ). This function was not affected by microinjection of the $\mathrm{SH} 3 \mathrm{C}$ domain alone (Fig. $8 \mathrm{C}$ ). In agreement with these results, synapses in Drosophila intersectin-null mutants displayed significantly lower levels of dynamin than wild type, supporting the idea that intersectin is involved in control of the amount of dynamin circulating at synapses (Koh et al., 2004).

During stimulation, both proteins reach the periactive zone (Fig. $8 \mathrm{~B}$ ). This migration was not affected by the antibody, thus indicating that dynamin and intersectin are recruited via independent, parallel pathways. It has been shown that the targeting of intersectin to the coat occurs via its Eps 15 interaction (Hussain et al., 2001). Several SH3 domain-containing proteins have been proposed to perform this function for dynamin (e.g., intersectin, amphiphysin, syndapin, and cortactin) (Shupliakov et al., 1997; Merrifield et al., 2005; Anggono et al., 2006). Although it remains to be clarified which of these $\mathrm{SH} 3$ domain proteins delivers dynamin to the periactive zone, it is evident that the delivery can be efficiently performed even when the intersectin-dynamin interaction is perturbed.

In the present study, we show that intersectin-dynamin interactions are important during fission in a vertebrate synapse. In agreement with previous studies in which dynamin-interacting SH3 domains were overexpressed in fibroblasts (Simpson et al., 1999), microinjection of the SH3C domain of intersectin in living reticulospinal synapses resulted in the inhibition of clathrinmediated endocytosis. This inhibition was accompanied by a reduction in dynamin immunoreactivity in the neck region of constricted coated pits. Surprisingly, an increase in dynamin levels around the necks of clathrin-coated pits after microinjection of intersectin antibodies was observed. Despite the presence of dynamin around the necks of coated pits, the fission reaction was inhibited. In vitro experiments with purified dynamin have demonstrated that the GTPase activity during oligomerization is strongly enhanced by an increase in dynamin concentration (Hinshaw, 2000). It cannot be excluded that intersectin antibodies accumulated at necks of constricted coated intermediates might create steric hindrance for dynamin assembly. Previous experiments, however, show that antibodies that interact with endocytic proteins localized to clathrin-coated intermediates, synaptojanin, and amphiphysin do not block fission (Haffner et al., 1997; Gad et al., 2000; Evergren et al., 2004b). We hypothesize that an active, defined positioning of dynamin, as well as of other components of the fission complex, is required for efficient membrane severing in vivo. Several $\mathrm{SH} 3$ domaincontaining proteins that are present in the fission complex have been implicated in this function (e.g., amphiphysin and endophilin) (Shupliakov et al., 1997; Gad et al., 2000). Our data indicate that intersectin is an important regulatory protein in this process. Spirals, observed at the necks of coated pits, were thinner after perturbation of intersectin $\mathrm{SH} 3$ do- 
A

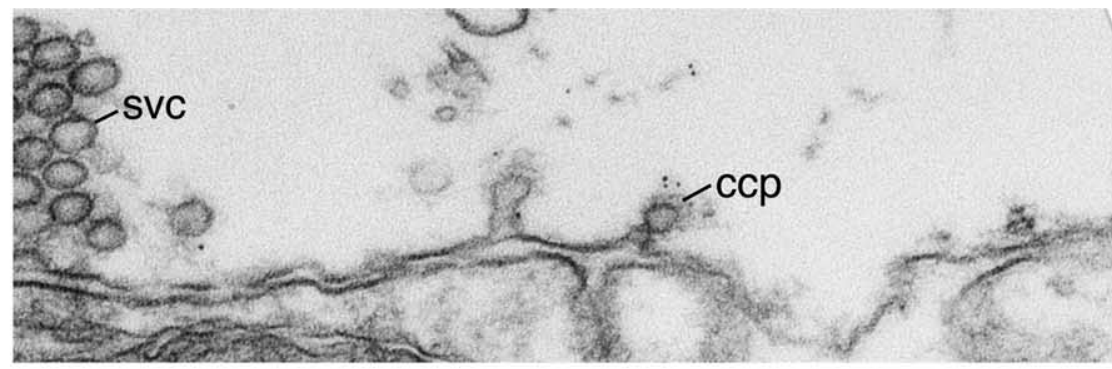

B

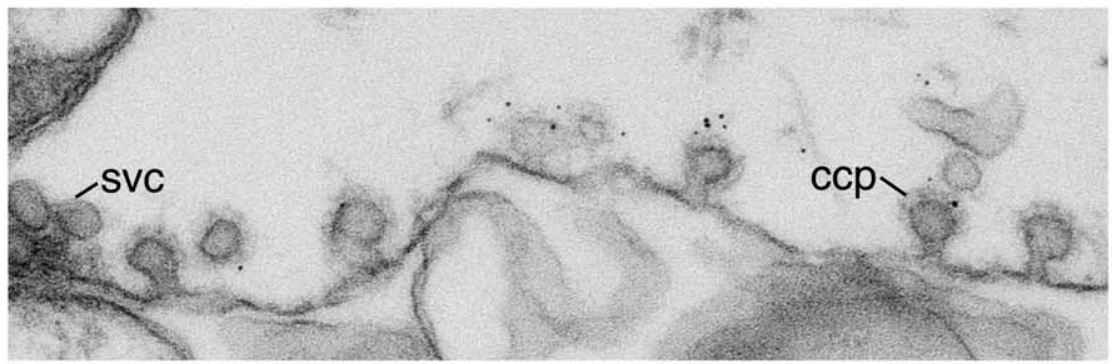

C
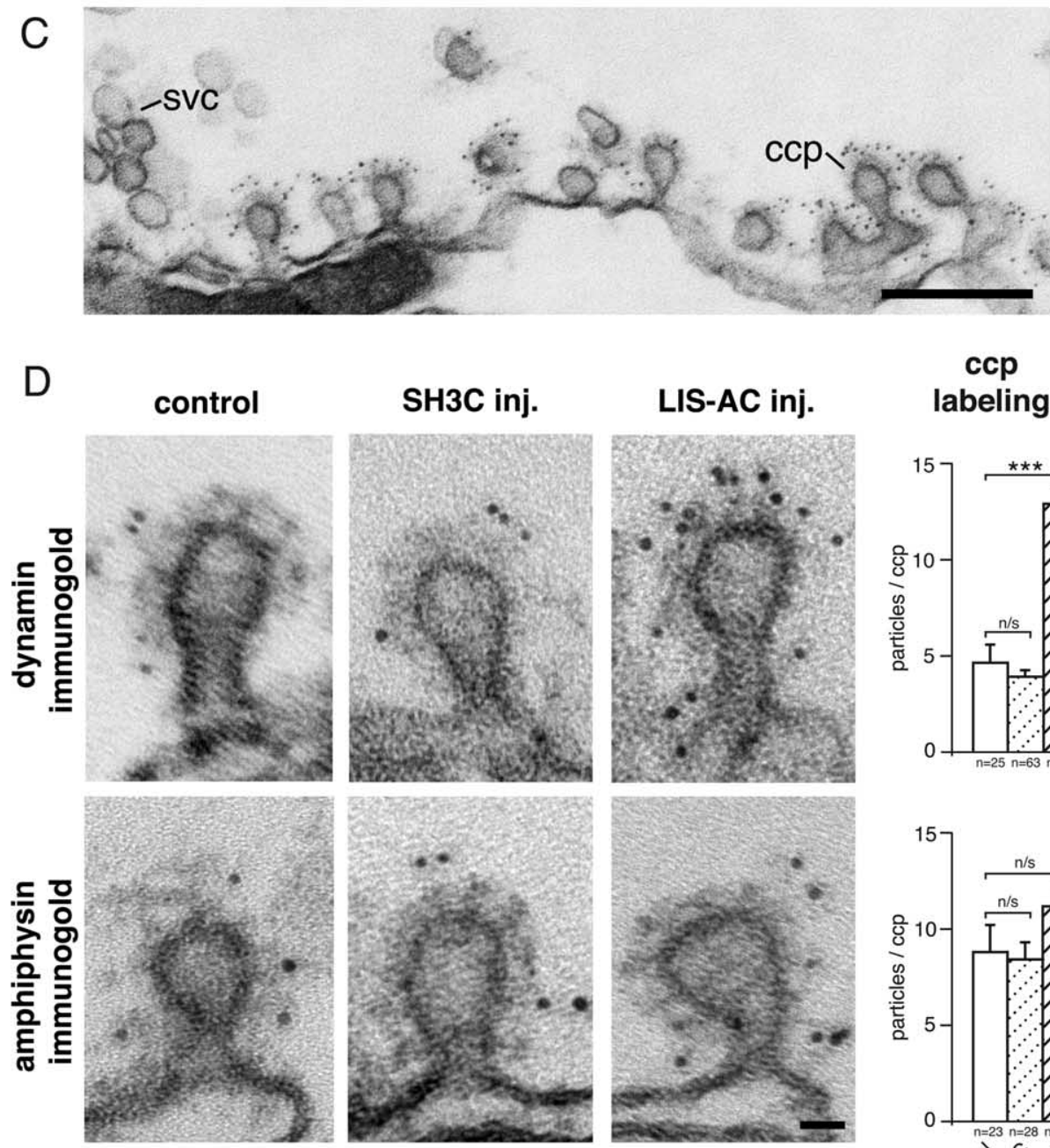

SH3C inj.
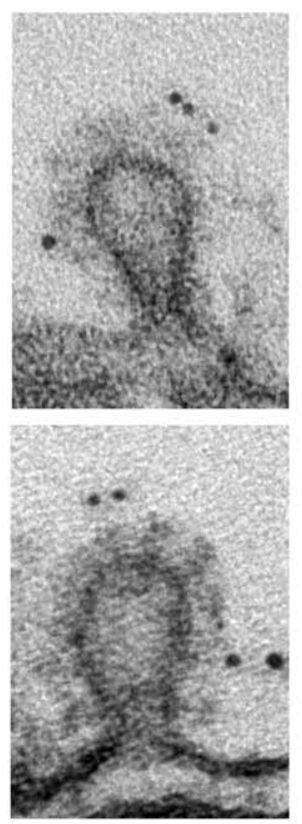

LIS-AC inj.
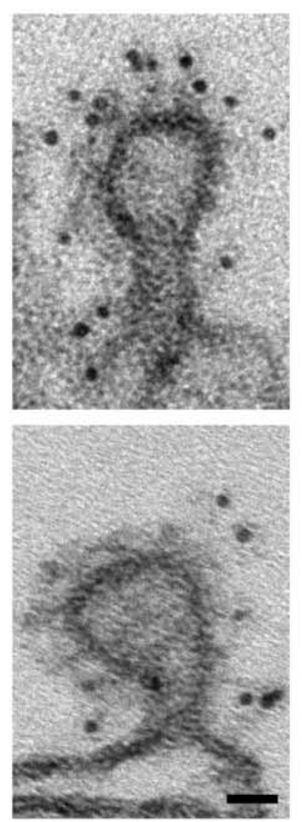

control, $5 \mathrm{~Hz}$, dynamin immunogold

\section{SH3C inj., $5 \mathrm{~Hz}$, dynamin immunogold}

\section{LIS-AC inj., $5 \mathrm{~Hz}$, dynamin immunogold}

\section{neck labeling}

Figure 7. Perturbation of intersectin-dynamin interactions results in changes in dynamin distribution at clathrin-coated pits. $A$-C, Low-power electron micrographs of periactive zones labeled with dynamin antibodies from a control synapse $(\boldsymbol{A})$, a GST-SH3C-injected synapse $(\boldsymbol{B})$, and a synapse at which LIS-AC antibodies were microinjected (C). D, Electron micrographs of coated intermediates from control synapses (far away from the microinjection site; first column) and from synapses at which GST-SH3C domain (second column) and LIS-AC antibodies (third column) were microinjected. Coated pits were immunolabeled using dynamin (top row) and amphiphysin (bottom row) antibodies. Note the increase in dynamin labeling on coated pits after LIS-AC microinjection compared with control. The quantification of average total labeling of clathrin-coated pits is shown in bar graphs in the fourth column, and the average labeling of the neck region is shown in bar graphs in the fifth column. Between 40 and 60 clathrin-coated pits per group were included in the quantification of dynamin labeling, and 23-50 clathrin-coated pits per group were included for amphiphysin labeling. Error bars represent SEs. $n$ represents the number of collared coated pits analyzed in each group. ${ }^{*} p<0.05$; ${ }^{* *} p<0.01$; ${ }^{* * *} p<0.0001$; two-tailed Student's $t$ test. Designations are the same as in Figures 3 and 4 . Scale bars: (in $\boldsymbol{C}) \boldsymbol{A}-\boldsymbol{C}, 0.2 \mu \mathrm{m} ; \boldsymbol{D}, 0.02 \mu \mathrm{m}$. 

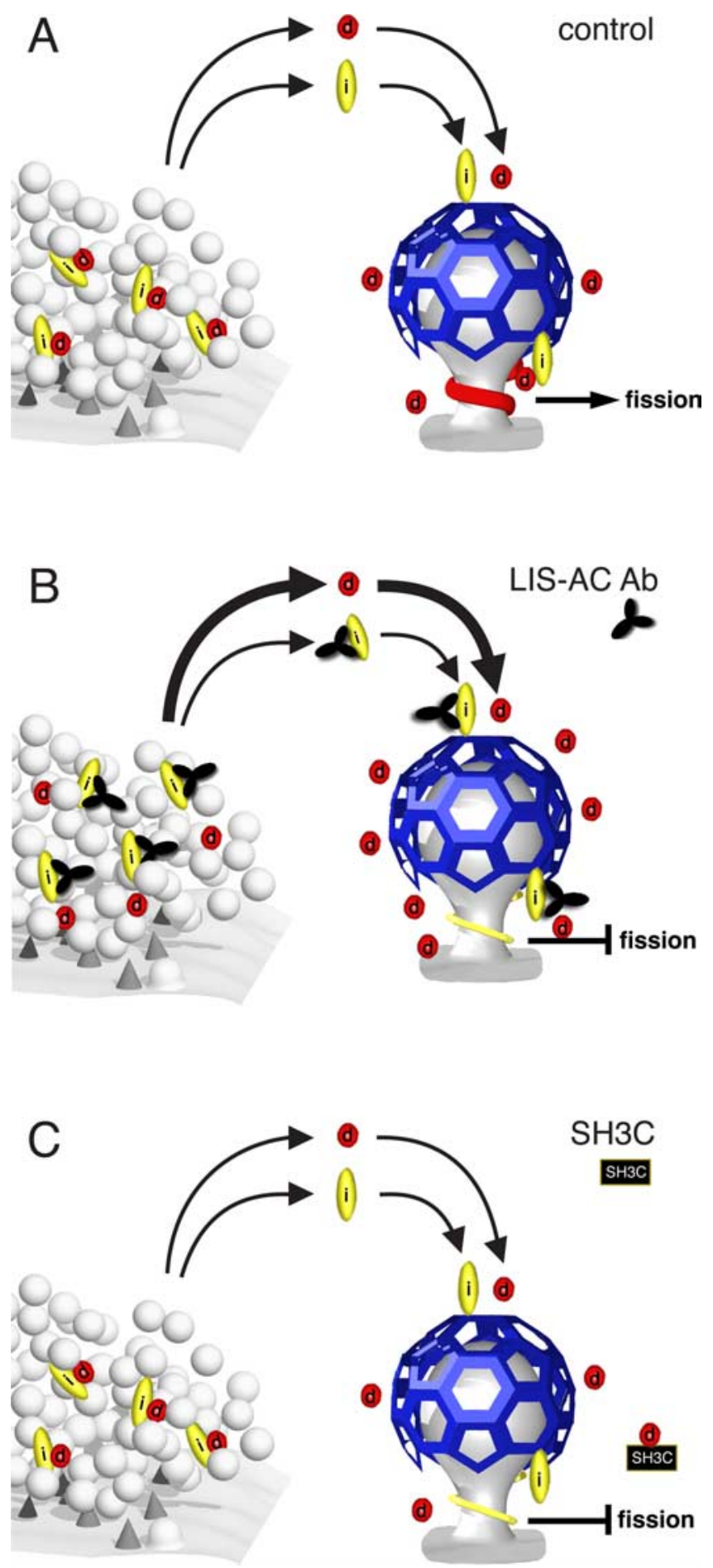

Figure 8. Intersectin functions as a negative regulator of dynamin recruitment to clathrincoated pits and directs dynamin to the fission complex. $\boldsymbol{A}$, Intersectin (i) and dynamin (d) are localized to the synaptic vesicle cluster and, during activity, redistribute to sites of endocytosis, at which they associate with clathrin-coated pits. Dynamin and other components of the fission complex assemble in a collar around the neck of the pit and sever the membrane. $\boldsymbol{B}$, Intersectin antibodies (Ab) perturb interactions with dynamin, leading to an increase in dynamin redistribution to endocytic zones. We hypothesize that intersectin acts as a negative regulator of dynamin recruitment to endocytic zones. Furthermore, blocking dynamin-intersectin interactions either by antibodies or with the GST-SH3 C domain resulted in formation of thinner fission complexes and an inhibition of membrane scission $(\boldsymbol{B}, \boldsymbol{C})$, thus suggesting that intersectin actively directs dynamin to the fission complex. As shown in synapses microinjected with the LIS-AC antibody $(\boldsymbol{B})$, it is not sufficient to have high amounts of dynamin at the membrane neck of clathrin-coated pits to achieve efficient fission; an active recruitment of dynamin to the neck seems to be required. main interactions than those observed after microinjection of GTP $\gamma \mathrm{S}$, suggesting that components of the fission complex were missing. In agreement with this finding, thin collars at the necks of coated pits were also observed in Drosophila NMJs in intersectin-null mutants (Koh et al., 2004). Perturbation of other SH3 domain-containing proteins (e.g., amphiphysin and endophilin) (Shupliakov et al., 1997; Gad et al., 2000) also resulted in an inhibition of fission. These intermediates had different morphological appearances from those observed after the perturbation of intersectin SH3 domain interactions, thus indicating that intersectin is involved at a step of the fission reaction distinct from those including amphiphysin and endophilin.

Intersectin interacts with several important proteins regulating actin polymerization (e.g., N-WASP and Cdc42) (Roos and Kelly, 1998; Hussain et al., 2001). Recent studies have shown that dynamin also interacts with proteins that function in actin regulation, such as cortactin and syndapin (Orth and McNiven, 2003; Merrifield et al., 2005; Anggono et al., 2006). In synapses at which intersectin-dynamin interactions were perturbed, we observe a reorganization of the actin matrix in the periactive zone. Thus, we suggest that the membrane infolds observed are a consequence of a loss of membrane rigidity normally provided by the cortical actin cytoskeleton. This notion is in agreement with data obtained from other model systems (Trifaro and Vitale, 1993; Qualmann et al., 2000; Itoh et al., 2005). It cannot be excluded that the actin reorganization observed after perturbation of intersectin interactions also reduces the efficiency of membrane scission. It has been suggested that polymerization of actin is important for creating a tension required for the dynamin-mediated scission of the membrane (Itoh et al., 2005; Roux et al., 2006).

Together, our data show that the release of dynamin to the periactive zone is regulated by intersectin interactions and that both proteins redistribute to the periactive zone, in which intersectin enhances dynamin-mediated fission. Our results demonstrate that the synaptic vesicle pool serves as an important compartment concentrating key components of the endocytic machinery, which relocate to the periactive zone during synaptic activity.

\section{References}

Anggono V, Smillie KJ, Graham ME, Valova VA, Cousin MA, Robinson PJ (2006) Syndapin I is the phosphorylation-regulated dynamin I partner in synaptic vesicle endocytosis. Nat Neurosci 9:752-760.

Bloom O, Evergren E, Tomilin N, Kjaerulff O, Löw P, Brodin L, Pieribone VA, Greengard P, Shupliakov O (2003) Colocalization of synapsin and actin during synaptic vesicle recycling. J Cell Biol 161:737-747.

Chen YJ, Zhang P, Egelman EH, Hinshaw JE (2004) The stalk region of dynamin drives the constriction of dynamin tubes. Nat Struct Mol Biol 11:574-575.

Cousin MA, Tan TC, Robinson PJ (2001) Protein phosphorylation is required for endocytosis in nerve terminals: potential role for the dephosphins dynamin I and synaptojanin, but not AP180 or amphiphysin. J Neurochem 76:105-116.

Deliagina TG, Fagerstedt P (2000) Responses of reticulospinal neurons in intact lamprey to vestibular and visual inputs. J Neurophysiol 83:864-878.

Estes PS, Roos J, van der Bliek A, Kelly RB, Krishnan KS, Ramaswami M (1996) Traffic of dynamin within individual Drosophila synaptic boutons relative to compartment-specific markers. J Neurosci 16:5443-5456.

Evergren E, Tomilin N, Vasylieva E, Sergeeva V, Bloom O, Gad H, Capani F, Shupliakov O (2004a) A pre-embedding immunogold approach for detection of synaptic endocytic proteins in situ. J Neurosci Methods 135:169-174.

Evergren E, Marcucci M, Tomilin N, Löw P, Slepnev V, Andersson F, Gad H, Brodin L, De Camilli P, Shupliakov O (2004b) Amphiphysin is a com- 
ponent of clathrin coats formed during synaptic vesicle recycling at the lamprey giant synapse. Traffic 5:514-528.

Evergren E, Zotova E, Brodin L, Shupliakov O (2006) Differential efficiency of the endocytic machinery in tonic and phasic synapses. Neuroscience 141:123-131.

Gad H, Ringstad N, Löw P, Kjaerulff O, Gustafsson J, Wenk M, Di Paolo G, Nemoto Y, Crun J, Ellisman MH, De Camilli P, Shupliakov O, Brodin L (2000) Fission and uncoating of synaptic clathrin-coated vesicles are perturbed by disruption of interactions with the SH3 domain of endophilin. Neuron 27:301-312.

Grabs D, Slepnev VI, Songyang Z, David C, Lynch M, Cantley LC, De Camilli P (1997) The SH3 domain of amphiphysin binds the proline-rich domain of dynamin at a single site that defines a new SH3 binding consensus sequence. J Biol Chem 272:13419-13425.

Granseth B, Odermatt B, Royle SJ, Lagnado L (2006) Clathrin-mediated endocytosis is the dominant mechanism of vesicle retrieval at hippocampal synapses. Neuron 51:773-786.

Guipponi M, Scott HS, Chen H, Schebesta A, Rossier C, Antonarakis SE (1998) Two isoforms of a human intersectin (ITSN) protein are produced by brain-specific alternative splicing in a stop codon. Genomics 53:369-376.

Gustafsson JS, Birinyi A, Crum J, Ellisman M, Brodin L, Shupliakov O (2002) Ultrastructural organization of lamprey reticulospinal synapses in three dimensions. J Comp Neurol 450:167-182.

Haffner C, Takei K, Chen H, Ringstad N, Hudson A, Butler MH, Salcini AE, Di Fiore PP, De Camilli P (1997) Synaptojanin 1: localization on coated endocytic intermediates in nerve terminals and interaction of its $170 \mathrm{kDa}$ isoform with Eps15. FEBS Lett 419:175-180.

Hinshaw JE (2000) Dynamin and its role in membrane fission. Annu Rev Cell Dev Biol 16:483-519.

Hussain NK, Yamabhai M, Ramjaun AR, Guy AM, Baranes D, O’Bryan JP, Der CJ, Kay BK, McPherson PS (1999) Splice variants of intersectin are components of the endocytic machinery in neurons and nonneuronal cells. J Biol Chem 274:15671-15677.

Hussain NK, Jenna S, Glogauer M, Quinn CC, Wasiak S, Guipponi M, Antonarakis SE, Kay BK, Stossel TP, Lamarche-Vane N, McPherson PS (2001) Endocytic protein intersectin-l regulates actin assembly via Cdc42 and N-WASP. Nat Cell Biol 3:927-932.

Itoh T, Erdmann KS, Roux A, Habermann B, Werner H, De Camilli P (2005) Dynamin and the actin cytoskeleton cooperatively regulate plasma membrane invagination by BAR and F-BAR proteins. Dev Cell 9:791-804.

Kent HM, McMahon HT, Evans PR, Benmerah A, Owen DJ (2002) Gamma-adaptin appendage domain: structure and binding site for Eps 15 and gamma-synergin. Structure 10:1139-1148.

Koh TW, Verstreken P, Bellen HJ (2004) Dap160/intersectin acts as a stabilizing scaffold required for synaptic development and vesicle endocytosis. Neuron 43:193-205.

Marie B, Sweeney ST, Poskanzer KE, Roos J, Kelly RB, Davis GW (2004) Dap160/intersectin scaffolds the periactive zone to achieve high-fidelity endocytosis and normal synaptic growth. Neuron 43:207-219.

Martina JA, Bonangelino CJ, Aguilar RC, Bonifacino JS (2001) Stonin 2: an adaptor-like protein that interacts with components of the endocytic machinery. J Cell Biol 153:1111-1120.

McPherson PS (2002) The endocytic machinery at an interface with the actin cytoskeleton: a dynamic, hip intersection. Trends Cell Biol 12:312-315.

Merrifield CJ, Perrais D, Zenisek D (2005) Coupling between clathrincoated-pit invagination, cortactin recruitment, and membrane scission observed in live cells. Cell 121:593-606.
Murthy VN, De Camilli P (2003) Cell biology of the presynaptic terminal. Annu Rev Neurosci 26:701-728.

Okamoto M, Schoch S, Südhof TC (1999) EHSH1/intersectin, a protein that contains EH and SH3 domains and binds to dynamin and SNAP-25. A protein connection between exocytosis and endocytosis? J Biol Chem 274:18446-18454.

Orth JD, McNiven MA (2003) Dynamin at the actin-membrane interface. Curr Opin Cell Biol 15:31-39.

Ottersen OP (1989) Postembedding immunogold labelling of fixed glutamate: an electron microscopic analysis of the relationship between gold particle density and antigen concentration. J Chem Neuroanat 2:57-66.

Pieribone VA, Shupliakov O, Brodin L, Hilfiker-Rothenfluh S, Czernik AJ, Greengard P (1995) Distinct pools of synaptic vesicles in neurotransmitter release. Nature 375:493-497.

Praefcke GJ, McMahon HT (2004) The dynamin superfamily: universal membrane tubulation and fission molecules? Nat Rev Mol Cell Biol 5:133-147.

Pucharcos C, Estivill X, de la Luna S (2000) Intersectin 2, a new multimodular protein involved in clathrin-mediated endocytosis. FEBS Lett 478:43-51.

Qualmann B, Kessels MM, Kelly RB (2000) Molecular links between endocytosis and the actin cytoskeleton. J Cell Biol 150:F111-F116.

Ringstad N, Gad H, Löw P, Di Paolo G, Brodin L, Shupliakov O, De Camilli P (1999) Endophilin/SH3p4 is required for the transition from early to late stages in clathrin-mediated synaptic vesicle endocytosis. Neuron 24:143-154.

Roos J, Kelly RB (1998) Dap160, a neural-specific Eps15 homology and multiple SH3 domain-containing protein that interacts with Drosophila dynamin. J Biol Chem 273:19108-19119.

Roos J, Kelly RB (1999) The endocytic machinery in nerve terminals surrounds sites of exocytosis. Curr Biol 9:1411-1414.

Roux A, Uyhazi K, Frost A, De Camilli P (2006) GTP-dependent twisting of dynamin implicates constriction and tension in membrane fission. Nature 441:528-531.

Sambrook J, Fritsch E, Maniatis T (1989) Molecular cloning: a laboratory manual, Ed 2. Cold Spring Harbor, NY: Cold Spring Harbor Laboratory.

Sengar AS, Wang W, Bishay J, Cohen S, Egan SE (1999) The EH and SH3 domain Ese proteins regulate endocytosis by linking to dynamin and Eps15. EMBO J 18:1159-1171.

Shupliakov O, Löw P, Grabs D, Gad H, Chen H, David C, Takei K, De Camilli P, Brodin L (1997) Synaptic vesicle endocytosis impaired by disruption of dynamin-SH3 domain interactions. Science 276:259-263.

Shupliakov O, Bloom O, Gustafsson JS, Kjaerulff O, Löw P, Tomilin N, Pieribone VA, Greengard P, Brodin L (2002) Impaired recycling of synaptic vesicles after acute perturbation of the presynaptic actin cytoskeleton. Proc Natl Acad Sci USA 99:14476-14481.

Simpson F, Hussain NK, Qualmann B, Kelly RB, Kay BK, McPherson PS, Schmid SL (1999) SH3-domain-containing proteins function at distinct steps in clathrin-coated vesicle formation. Nat Cell Biol 1:119-124.

Tong XK, Hussain NK, Adams AG, O’Bryan JP, McPherson PS (2000) Intersectin can regulate the Ras/MAP kinase pathway independent of its role in endocytosis. J Biol Chem 275:29894-29899.

Trifaro JM, Vitale ML (1993) Cytoskeleton dynamics during neurotransmitter release. Trends Neurosci 16:466-472.

Zamanian JL, Kelly RB, Hutchings NJ, Clarkson N, Chalkley R, Barclay AN, Brown MH, Cormont M, Meton I, Mari M, Monzo P, Keslair F, Gaskin C, McGraw TE, Le Marchand-Brustel Y, Stamenova SD, Dunn R, Adler AS, Hicke L, Angers A, et al. (2003) Intersectin 1L guanine nucleotide exchange activity is regulated by adjacent src homology 3 domains that are also involved in endocytosis. Mol Biol Cell 14:1624-1637. 